\title{
Contribución a la obra de un discípulo de Diego de Mora: Atanasio Tribaldos y la imaginería del retablo mayor de la parroquia de la Asunción de Luque (Córdoba)
}

\author{
Juan Luque Carrillo \\ Universidad de Sevilla \\ juanluque317@gmail.com
}

En 1987 aportó la profesora Raya la revisión más exhaustiva y documentada sobre la realidad y trascendencia del retablo barroco cordobés. En ella planteaba magistralmente la situación de los estudios que sobre el retablo barroco se han realizado en la ciudad de Córdoba y cuál fue su desarroIlo y evolución (Raya, 1987). Paralelamente analiza los elementos fundamentales que constituyen esta manifestación plástica: materiales, plantas, soportes, hornacinas, motivos decorativos, etc., tanto en el marco de la capital, como en los diferentes puntos de la Campiña Sur y la Subbética, con ejemplos de especial interés que repercutieron en el desarrollo del Barroco en la ciudad. Aunque la autora recoge parte de la documentación referente a las obras del retablo mayor de la parroquia de Nuestra Señora de la Asunción de Luque, no será hasta 1993 cuando Estrada Carrillo presente por vez primera toda la relación documental de dicha obra, en un minucioso trabajo monográfico donde describe todo su proceso constructivo, informando acerca de los maestros que llevaron a cabo su ejecución y señalando las cronologías de los principales escultores que trabajaron en su ornamentación (Estrada, 1993). De igual modo, Estrada analiza las intervenciones de los arquitectos renacentistas Sebastián de Peñarredonda, Hernán Ruiz III y Juan de Ochoa en las distintas fases constructivas del templo, hasta su terminación en 1597-98.

Posteriormente, con motivo del tercer centenario del nacimiento del escultor andaluz Andrés de Carvajal, la profesora Gómez Román publicó en 2014 un interesante estudio sobre la figura del escultor Diego de Mora y la proyección de su taller en la Granada de los siglos XVII y XVIII, donde analiza el origen del obrador, así como sus principales singularidades, componentes y discípulos que continuaron la actividad artística durante el Setecientos, caso de Atanasio Tribaldos, entre otros (Gómez, 2014).

Según esta línea, el presente trabajo parte de sendos estudios monográficos y de la información suministrada por la propia documentación del archivo parroquial de Luque, pudiendo contrastar el inicio, proceso de ejecución y decoración final de su retablo.

\section{Notas sobre la edificación del retablo}

Interesante punto de partida para iniciar el estudio de la obra es el testimonio de la visita general del 24 de enero de 1666. Se trata de la información facilitada por don Martín Álvarez de Sotomayor, visitador de la diócesis cordobesa, que recoge en su escrito pastoral el proyecto de erección de un retablo para la iglesia mayor de Luque, dado que en aquel momento solo existía un pequeño tabernáculo de piedra que, en determinadas celebraciones, asumía la función de manifestador.

Poco tiempo después del regreso a Córdoba del mencionado visitador, el proyecto fue aprobado. Tras hacer pública la noticia, se encargó un primer dibujo al carpintero local Francisco de Villena (Estrada, 1993: 81). Puntualmente cumplió el artista con el encargo y, antes de diciembre de 1667, presentó el diseño del retablo, por el que cobró 75 reales ${ }^{1}$. No obstante, este trabajo no debió de convencer a la autoridad diocesana puesto que, siete años más tarde, Bartolomé de Acisclo Baena reflejó en las cuentas una suma de 1.600 reales en concepto del pago ejecutado al arquitecto granadino José Granados de la Barrera, por los viajes que hizo a Luque y la planta de un retablo de piedra que trazó para el altar mayor ${ }^{2}$. La presencia de este arquitecto, y el 
encargo en sí, implica un cambio en la propuesta original, que era hacerlo de madera. El que Granados de la Barrera hiciera más de un viaje a Luque y formalizara un proyecto, es prueba fehaciente de que el encargo se debía a una idea madurada que, por segunda vez y sin conocerse el motivo, se abandonó. Finalmente en 1678 se retomó la idea primigenia: hacer el retablo en madera.

Rápidamente el vicario publicitó la obra por un plazo de 30 días, para presentar las propuestas. Hubo dos aspirantes a formalizar el trabajo: el maestro Simón Sánchez, de Granada, y por otro lado el cordobés Acisclo Manuel Muñoz. Los dos artistas ofrecieron hacerlo por la misma cantidad: 44.000 reales $^{3}$.

Meses después, el visitador general decretó que la obra debía ser encargada a Acisclo Manuel Muñoz, respetando la cantidad fijada. Seguidamente el proyecto pasó a información del obispo, en aquel momento Fray Alonso de Salizanes y Medina (Gómez, 1778: 709), y se procedió a hacer pública su ejecución ${ }^{4}$. Según las condiciones pactadas, el retablo debía tallarse en Luque, penalizando el absentismo con dos ducados por día. Para hacer frente a los gastos previstos, se autorizó la venta de 531 fanegas y medio cuartillo de trigo, así como de 537 fanegas, 9 celemines y 3 cuartillos de cebada (Estrada, 1993: 83).

Las obras del retablo evolucionaron lentamente. La falta de liquidez llegó incluso a protagonizar serios desencuentros entre Muñoz y la fábrica parroquial, que durante algunos meses se vio en bancarrota y embargada de sus bienes. Con objeto de solventar esta situación, el obrero Francisco Blanco de la Nava se desplazó a Córdoba e informó a la autoridad diocesana del problema derivado de la traza del retablo. Como solución, se entregaron al maestro 30 fanegas de trigo, 2.350 reales y 21 maravedíes ${ }^{5}$.

Si se toman como base los extractos de los libros de cuentas de fábrica, la terminación del retablo presenta ciertas dudas de fijación ya que, según los pagos de los alquileres de la casa en que vivió el maestro, los registros constatados muestran abonos que abarcan desde primeros de octubre de 1678 hasta finales de 1685. Sin embargo, en las cuentas tomadas el 27 de junio de 1685, con motivo de sendas liquidaciones que se hacen al artista, se expresa «maestro que hiço el retablo» y «maestro que ha hecho el retablo desta yglesia», en afirmación clara de que en esa fecha estaba terminado (Estrada, 1993: 85).
Finalmente, la respuesta exacta la da la inscripción escrita detrás del medallón del Espíritu Santo, descubierta por unos restauradores en 1992, que cabalmente fija el año de «1685, año en que se acabo este rretablo en el mes de maio en $23 »^{6}$, tres años después de la fecha señalada.

\section{1705-1707: Atanasio Tribaldos y la terminación del programa iconográfico}

El texto de la visita de 1678 incluye una interesante descripción de la traza del retablo, donde se analizan los dos cuerpos, tres calles, elementos sustentantes y decorativos, y se especifica que contenía solamente los nichos para albergar las imágenes que más tarde el obispo, o su visitador, determinaran. Así en 1683, don Jacinto de Alcántara y Leiva, visitador del Obispado y vicario de la localidad de Cabra, dictó las condiciones que habrían de figurar en el contrato de la obra de la decoración del retablo: diez imágenes de madera, sin especificar las iconografías, por la cantidad de 13.500 reales de toda costa y cuatro años para pagarlas y hacer la entrega (Estrada, 1993: 86)

Para llevar a cabo este proyecto de decoración se llamó al escultor cordobés Manuel de Miranda, del que apenas hemos localizado referencias en la documentación parroquial, y casi todas ellas para denotar un incumplimiento manifiesto en lo atribuible a su trabajo. Resultó que, pasados los cuatro años, Miranda únicamente presentó tres de las diez tallas encargadas: el Crucificado del Calvario y las esculturas de san Pedro y san Pablo del segundo cuerpo (Luque, 2014: 211-217). Dado el contratiempo, la fábrica parroquial no dudó en destituir al maestro de su encargo y, liquidada la cuenta, confiar el resto de la decoración a otro artista, siendo a partir de este momento cuando se incorpora la personalidad de Atanasio Tribaldos.

Adjudicada la tarea al maestro granadino, el vicario y obrero de la fábrica parroquial dieron órdenes de cómo debía concluirse la decoración, señalando las imágenes que habían de completar el programa iconográfico, obligándose el escultor a entregar el encargo en el plazo máximo de un año (Luque, 2014: 211-217). La escritura del concierto se extiende en noviembre de 1705, y en ella se especifican las cinco tallas con las que se completó dicha ornamentación: la Asunción, de cinco cuartas de altura; san Bartolomé y San- 
tiago, de dos varas, y dos ángeles, de una vara cada uno. El precio fijado fue de 400 ducados, efectivos en una sola paga realizada en Granada. A ello hay que añadir el envío del dinero, que costó 80 reales (Estrada, 1993: 88).

Firmado el contrato, el escultor hizo un primer viaje a Luque, donde conoció de primera mano el retablo para el que había de realizar las imágenes, analizó la obra en su conjunto y pudo compartir impresiones al respecto con el vicario y obrero de la fábrica parroquial. Realizada esta visita, el maestro regresó a su taller, próximo a la albaicinera iglesia de san Nicolás, donde trabajó ininterrumpidamente desde noviembre de 1705, hasta mediados de 1707 en la talla de las citadas esculturas. Una vez terminadas las imágenes, el vicario designó a un maestro perito para el reconocimiento de su calidad, desplazándose a Granada para examinarlas. La opinión de este segundo artista confirmó el buen trabajo de Tribaldos, que abordó el encargo con seriedad y un excelente acabado ${ }^{7}$. Días después, preparado el traslado de las imágenes, se procedió al viaje con destino a Luque, y con él, se concluyó el proceso decorativo del retablo.

En la imagen de la Asunción Tribaldos presenta una talla de unos 110 centímetros aproximadamente, de pie, con las manos sobre el pecho y la cabeza ligeramente levantada. Se trata de una escultura llena de sencillez contrastada por la cantidad de detalles que presenta, lo que ayuda a plasmar en ella un gran realismo que no pasa inadvertido. A pesar de tratarse de una escultura que concentra gran espiritualidad, su policromía es suave y sobria, careciendo de tonalidades excesivamente oscuras y contrastes que puedan distraer la atención del fiel. Esto hace que dirijamos toda la atención al foco de mayor expresividad de la figura: el rostro, enmarcado por los mechones rizados del cabello. Finalmente el movimiento también está presente en la obra, plasmado en el detalle de la pierna izquierda adelantada respecto a la contraria. En la peana, tres angelitos desnudos juguetean entre nubes, aportando dinamismo, ingenuidad y teatralidad a la obra [1]

Si comparamos esta imagen con las esculturas de san Bartolomé y Santiago el Mayor, encontramos grandes similitudes, aunque podemos advertir un mayor realismo y expresividad en el caso de los apóstoles. Del primero podemos decir que se trata de un delicado anciano de bellas proporciones y un acusado simbolismo, especialmente visible en la afligida actitud del rostro y postura del tronco [2].

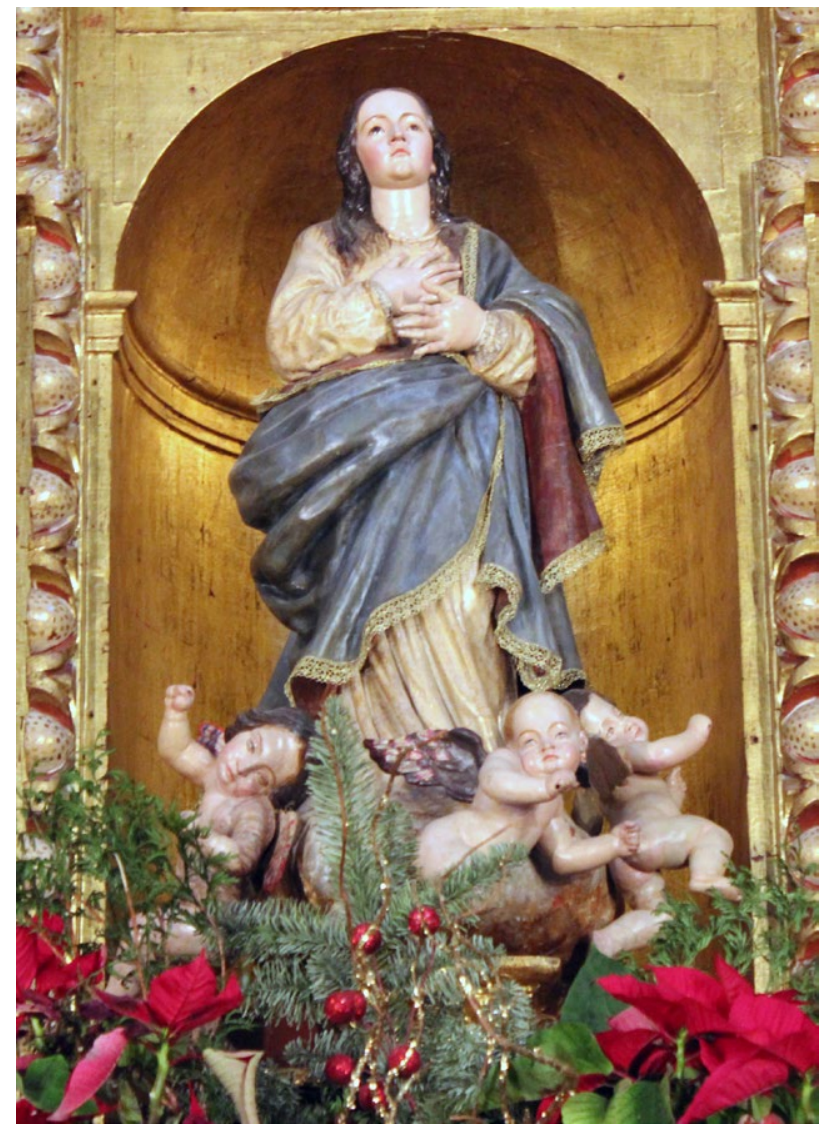

1. Atanasio Tribaldos, Asunción, 1707. Retablo mayor de la parroquia de la Asunción, Luque, Córdoba. Foto: Juan Luque Carrillo

La posición del santo es claramente frontal, sin curvas, ni contrapposto que alteren el equilibrio compositivo. Viste el apóstol una túnica ceñida a la cintura, con pliegues de gran simetría y linealidad y, sobre la espalda, un manto ocre con el que cubre parte del tronco. Porta en su mano derecha el cuchillo, símbolo del martirio, mientras que con la izquierda muestra un gesto de intensa contorsión, pudiendo apreciar una especial tensión en la palma de la mano. Finalmente, adelanta la pierna izquierda respecto a la derecha, dejando ver incluso parte del pie bajo la túnica que modela la silueta y contornea su figura.

En la misma línea vemos a Santiago apóstol, una imagen de gran espiritualidad y serenidad, marcada por un intencionado realismo que incita a su contemplación. Al igual que su compañero, viste túnica oscura y manto ocre pero, 


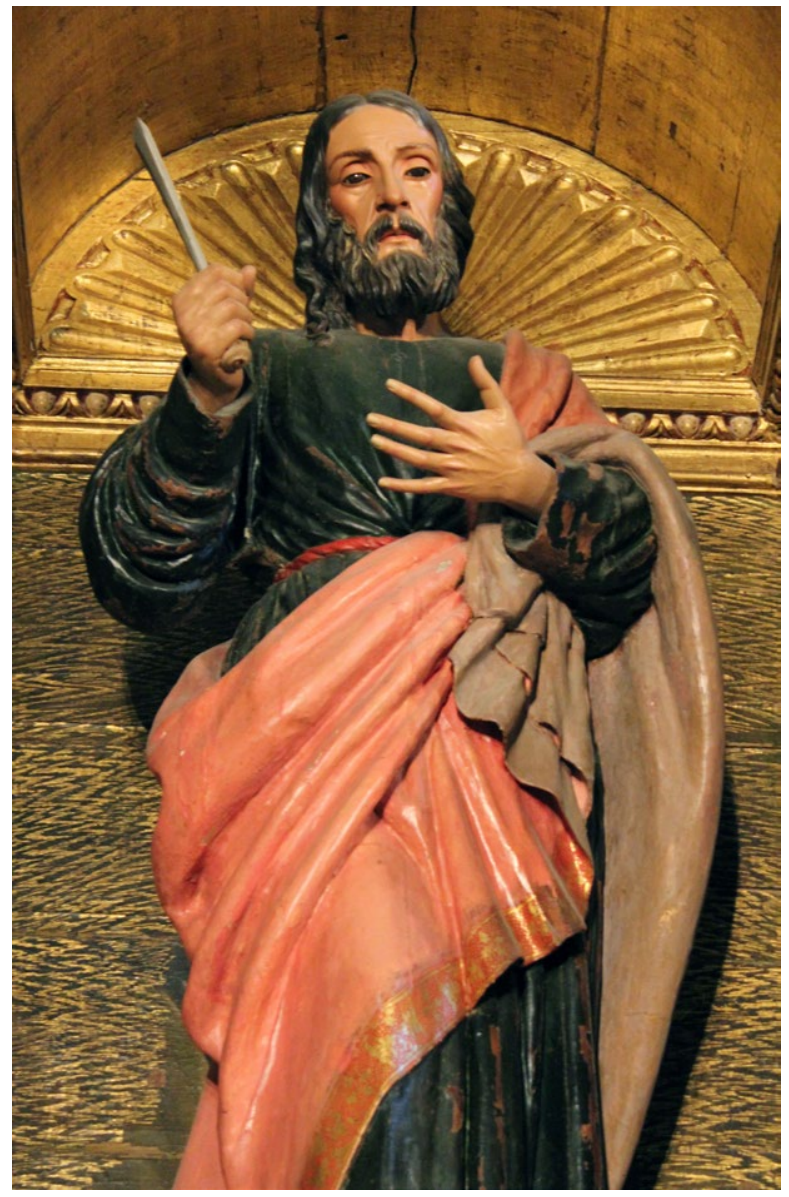

a diferencia del primero, cubre además su espalda con una pequeña muceta con la venera en el hombro izquierdo [3]. Vemos en la obra una marcada verticalidad, acrecentada por el bordón -o bastón de peregrino- (Réau, 1997: 176) que el apóstol sostiene en su mano izquierda y que le sirve de apoyo para sostener el peso del cuerpo. El rostro refleja un especial simbolismo, acentuado por los rasgos maduros y la expresión de cansancio a consecuencia de la edad avanzada. Finalmente oprime con tensión su mano derecha sobre el pecho, a la vez que adelanta el pie contrario, generando un tímido movimiento apenas visible.

Por último, respecto a los ángeles, su función de atlantes y ubicación en la cornisa del ático condicionan tanto su posición, como la simplicidad compositiva [4]. El canon es de formas redondas y carnosas, con una anatomía infantil de vientre y piernas abultadas. Los rostros son demasiado hieráticos y poco expresivos, quedando definidos por unos ojos almendrados que, en ambos casos, recuerdan ciertos

2. Atanasio Tribaldos, San Bartolomé, 1707.

Retablo mayor de la parroquia de la Asunción,

Luque, Córdoba. Foto: Juan Luque Carrillo

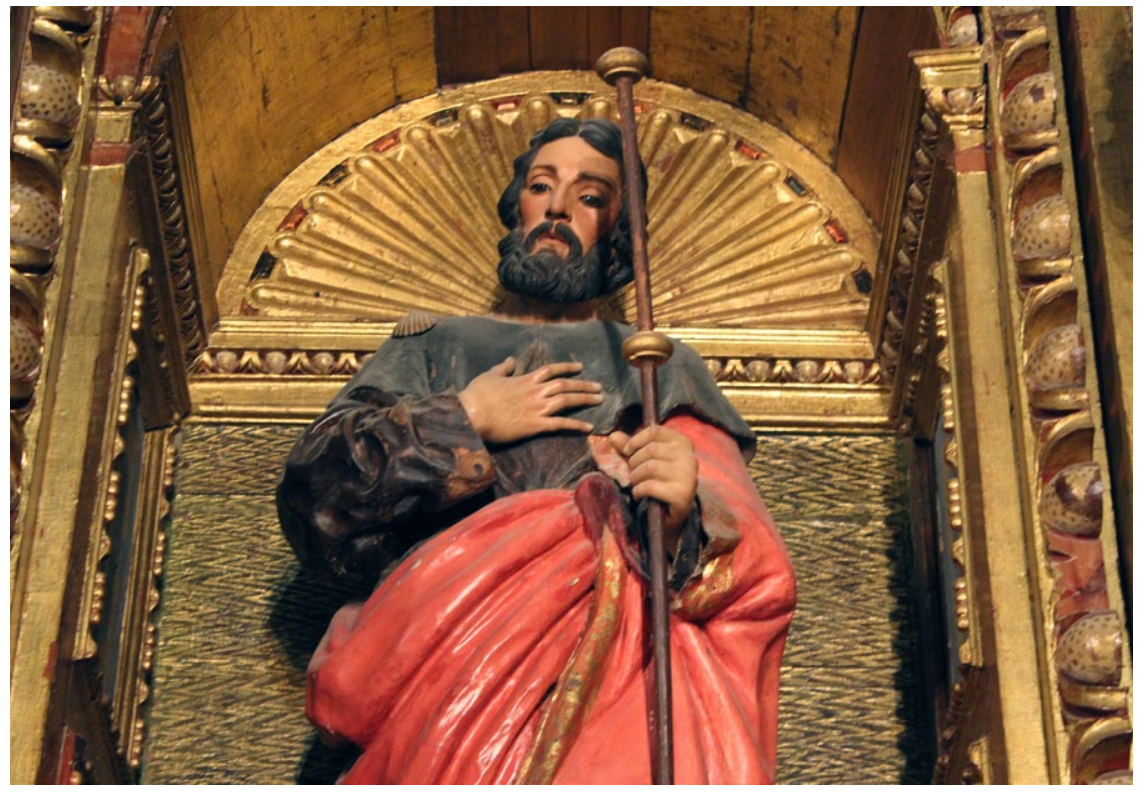

3. Atanasio Tribaldos, Santiago, 1707. Retablo mayor de la parroquia de la Asunción, Luque, Córdoba. Foto: Juan Luque Carrillo 
4. Atanasio Tribaldos. Ángeles,

1707. Retablo mayor de la parroquia de la Asunción, Luque, Córdoba. Foto: Juan Luque Carrillo

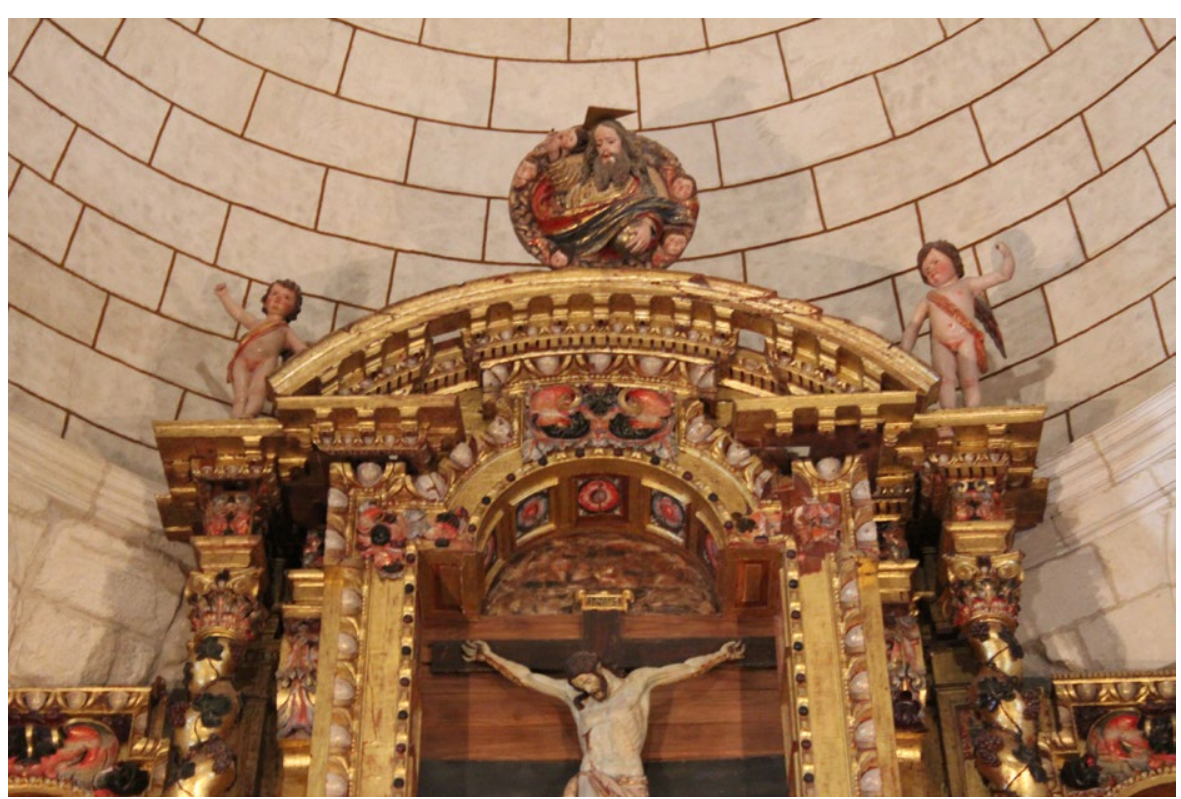

arcaísmos medievalistas. Únicamente visten una banda ocre entrecruzada por el pecho, con nudo en la cadera derecha. Como en los ejemplos anteriores, Tribaldos repite la misma sensación de movimiento mediante el recurso de adelantar una pierna respecto a la otra, en estos dos casos prácticamente inapreciable debido a la altura de la cornisa.

Concluye así la decoración del retablo mayor de la iglesia parroquial de Luque, una obra de gran contenido doctrinal y riqueza iconográfica que consta de banco, dos cuerpos con tres calles perfectamente marcadas, y ático coronado con un medallón de Dios Padre ${ }^{8}$. Grandes columnas salomónicas decoradas con ricos motivos eucarísticos y vegetales, separan cuerpos y calles. Precisamente en este aspecto radica el interés compositivo e iconológico de la obra, al tratarse de uno de los retablos pioneros de la provincia cordobesa en incorporar este tipo de fuste para articular espacios y módulos, aunque estructuralmente no innove nada en lo ya conocido en estos momentos de impulso y consolidación del Barroco pleno andaluz (Raya, 1987: 396).
Al fin, tras el traslado y posterior colocación de las imágenes en sus respectivas hornacinas, se procedió a la firma del recibo de cobro, que tuvo lugar en Luque el 10 de agosto de $1707^{\circ}$. Finaliza de este modo la decoración del retablo y no volvemos a encontrar referencias del escultor granadino en la documentación parroquial, desconociendo cómo terminó su trayectoria profesional y en qué circunstancias vivió hasta 1730, año en que aparece empadronado por última vez -según investigó Gómez Román-, en la granadina calle del Pilar Seco, en el Albaicín (Gómez, 2014: 186199). Con la obra de Atanasio Tribaldos se completó, pues, la imaginería y programa iconográfico del retablo mayor de la parroquia de la Asunción de Luque, y con él, uno de los mejores exponentes de la retablística cordobesa de finales del seiscientos-principios del XVIII. Confiemos en que la revisión documental contribuya al conocimiento y trayectoria del maestro, y a situar su actividad profesional en el lugar que justamente le corresponde dentro del estudio de la escultura granadina del primer tercio del Setecientos. 


\section{Notas}

1 Archivo Parroquia Nuestra Señora de la Asunción, Luque (APNSA, Luque), Cuentas de Fábrica. Lib. 5, Año 1667, s. f.

2 APNSA, Luque, Lib. 7, Año 1674, s. f.

3 APNSA, Luque, Lib. 8, Año 1678, s. f.

4 APNSA, Luque, Lib. 8, Año 1678, s. f.

5 APNSA, Luque, Lib. 10, Año 1687, s. f.

6 En 1993 Estrada Carrillo transcribió erróneamente esta inscripción, en: ESTRADA CARRILLO, Vicente (1993), La iglesia parroquial de Luque (1567-1992), Excma. Diputación Provincial, Córdoba. p. 86

7 APNSA, Luque, Cuentas de fábrica, Libro 12, año 1707, s. f.

8 Junto a las esculturas de Tribaldos, completan el programa iconográfico las tres tallas de Manuel de Miranda y dos óleos sobre lienzo, anónimos, con las representaciones de la Virgen y san Juan, pertenecientes al calvario del cuerpo superior.

9 APNSA, Luque, Cuentas de Fábrica, Lib. 14, años 1705-1707, s. f.

\section{Bibliografía}

ESTRADA CARRILLO, Vicente (1993), La iglesia parroquial de Luque (1567-1992), Diputación Provincial de Córdoba, Córdoba.

GÓMEZ BRAVO, Juan (1778), Catálogo de los obispos de Córdoba y breve noticia histórica de su iglesia catedral y obispado, Oficina de D. Juan Rodríguez, Córdoba.

GÓMEZ ROMÁN, Ana María (2014), «Diego de Mora y su taller», en Actas del I Congreso andaluz sobre Patrimonio Histórico: La escultura barroca andaluza en el siglo XVIII. Conmemoración del III Centenario del nacimiento del escultor Andrés de Carvajal y Campos (17092009), Estepa, 17-18 de septiembre de 2009, pp. 186-199.

LUQUE CARRILLO, Juan (2014), «El retablo de Luque (Córdoba): un proyecto de Pedro Roldán "el Mozo” y otros datos", Boletín del Seminario de estudios de arte y arqueología, Universidad de Valladolid, n. ${ }^{\circ}$ 80, pp. 211-217.

RAMÍREZ DE ARELLANO, Rafael y DÍAZ DE MORALES, Rafael (1893), "Diccionario biográfico de artistas de la provincia de Córdoba", en MARQUÉS DE LA FUENSANTA DEL VALLE (dir.), Colección de documentos inéditos para la historia de España, Imprenta de José Perales y Martínez, Madrid.

RAYA RAYA, María de los Ángeles (1987), El retablo barroco cordobés, Monte de Piedad y Caja de Ahorros de Córdoba, Córdoba. RÉAU, Louis (1997), Iconografía del arte cristiano, tomo 2, vol. 5: Iconografía de los santos, P-Z, Serbal, Barcelona. 